\title{
Comportamento ingestivo diurno de novilhas de corte recebendo níveis de suplemento
}

\author{
Diurnal ingestive behavior of beef heifers receiving levels of supplement \\ Stefani Macari ${ }^{I}$ Marta Gomes da Rocha' ${ }^{I I}$ Luciana Pötter ${ }^{I}$ Juliano Roman ${ }^{I}$ \\ Carolina Bremm ${ }^{\mathrm{I}}$ Vagner Guasso da Costa ${ }^{\mathrm{I}}$
}

\section{RESUMO}

\begin{abstract}
Este trabalho foi conduzido com o objetivo de avaliar a composição botânica da pastagem e o comportamento ingestivo diurno de bezerras de corte recebendo diferentes níveis de suplemento. Os animais foram mantidos em pastagem de aveia preta (Avena strigosa Schreb.) e azevém (Lolium multiflorum Lam.), recebendo ração comercial nos níveis de 0;0,3; 0,6 e 0,9\% do peso vivo (PV). Em quatro datas, foram registradas as atividades diurnas de pastejo, ruminação, ócio, número de visitas e tempo de permanência no cocho e taxa de bocadas. Com aumento dos níveis de suplemento, houve redução no tempo de pastejo e aumento no tempo de ócio $(P<0,05)$. A taxa de bocada e o peso de bocado foram afetados pelo suplemento e ciclo da pastagem $(P<0,05)$. O tempo diurno de ruminação não foi afetado pelo fornecimento de suplemento $(P>0,05)$. A composição botânica e estrutural da pastagem é influenciada pelos níveis de suplemento utilizados e o ciclo de produção das forrageiras.
\end{abstract}

Palavras-chave: taxa de bocada, tempo de pastejo, peso de bocado, composição botânica.

\section{ABSTRACT}

The trial was conducted aiming to evaluate pasture botanical composition and diurnal ingestive behavior of beef heifers receiving different supplement levels. The animals were kept in black oats (Avena strigosa Schreb.) and Italian ryegrass (Lolium multiflorum Lam.) pasture, receiving 0; 0.3; 0.6 and $0.9 \%$ of live weight ( $L W$ ) of supplement. The supplement utilized was a commercial ration. In four dates were registrated diurnal activities of grazing, ruminating, idle, number of visits and trough permanence time and bite rate. Increasing supplement levels reduced grazing time and increased idle time $(P<0.05)$. Bite rate and bite weight were affected by the supplement and pasture cycle $(P<0.05)$. Ruminating time was not affected by supplement levels $(P>0.05)$. Botanical and structural composition of pasture were influenced by supplement levels and related with herbage production cycle $(P>0.05)$.

Key words: bite rate, grazing time, bite weight, botanic composition.

\section{INTRODUÇÃO}

Plantas forrageiras são adaptadas ao pastejo e os animais as consomem de forma seletiva, dando preferência por partes tenras e mais nutritivas, em detrimento do material estrutural e senescente. $\mathrm{O}$ estudo da distribuição espacial e temporal dos componentes botânicos da pastagem visa a compreender o comportamento das forrageiras dentro de seu ciclo de produção e, conseqüentemente, a resposta animal diante da quantidade e qualidade da forragem que é ofertada.

As massas de folhas e colmos são os principais componentes da massa de forragem, bem como da oferta de forragem e, quando presentes em quantidades adequadas, asseguram aos animais em pastejo uma boa capacidade de seleção, apreensão, consumo e, conseqüentemente, bom desempenho animal (ROSO et al., 2003).

Há vários fatores que podem interferir nas atividades diárias dos animais em pastejo, como

IPrograma de Pós-graduação em Zootecnia, Universidade Federal de Santa Maria (UFSM), Santa Maria, RS, Brasil.

IIDepartamento de Zootecnia, UFSM. Endereço para correspondência: Rua Tuiuti, 1554, 201, 97015-662, Santa Maria, RS, Brasil. E-mail: mgdarocha@gmail.com. 
características da pastagem, manejo, condições climáticas e atividade dos animais em grupo. Esses fatores podem proporcionar alterações no tempo de pastejo e ou consumo de forragem, afetando o desempenho animal e, conseqüentemente, a eficiência do sistema produtivo (BREMM et al., 2004).

O conhecimento dos mecanismos do processo de pastejo é importante para entender o controle do consumo pelos animais. Os principais componentes do comportamento em pastejo são tempo de pastejo, taxa de bocadas e tamanho do bocado, que, no seu conjunto, determinam o consumo diário de forragem pelos animais em pastejo (JAMIESON \& HODGSON, 1979a).

Quando os animais são suplementados, novas variáveis interferem no consumo de nutrientes e estão associadas às relações de substituição de forragem por suplemento e/ou à adição no consumo total de matéria seca, que mudam conforme as características da base forrageira e do suplemento (HODGSON, 1990). Entre os efeitos da suplementação no comportamento ingestivo, destaca-se a mudança no tempo de pastejo (BREMM et al., 2005), que é freqüentemente diminuído.

O presente trabalho foi desenvolvido com o objetivo de avaliar a composição botânica e estrutural da pastagem e o comportamento ingestivo diurno de bezerras de corte em pastagem de aveia (Avena strigosa Schreb.) e azevém (Lolium multiflorum Lam.), recebendo diferentes níveis de suplemento.

\section{MATERIAL E MÉTODOS}

O experimento foi conduzido em área pertencente ao Departamento de Zootecnia da Universidade Federal de Santa Maria (UFSM), na Depressão Central do Rio Grande do Sul. A área experimental foi dividida em oito potreiros, cada um com aproximadamente 0 ,7ha, totalizando 6,3ha e mais uma área anexa de 1,0ha para permanência dos animais reguladores.

A pastagem foi implantada pelo sistema de plantio convencional em 19/05/2004. A semeadura e a adubação de plantio foram realizadas a lanço com uma semeadora centrífuga. A densidade utilizada foi de $80 \mathrm{~kg}$ $\mathrm{ha}^{-1}$ de aveia (Avena strigosa Schreb.) e $50 \mathrm{~kg} \mathrm{ha}^{-1} \mathrm{de}$ azevém (Lolium multiflorum Lam.). No plantio foram utilizados $250 \mathrm{~kg} \mathrm{ha}^{-1}$ de adubo da fórmula 05-20-20 (NPK). Em cobertura, foram aplicados $70 \mathrm{~kg} \mathrm{ha}^{-1}$ de nitrogênio, na forma de uréia, em três aplicações, nos dias 23/06, 04/08 e 30/08/2004.

O período de estabelecimento da pastagem foi de 50 dias. O sistema de pastejo foi contínuo, com taxa de lotação variável, sendo utilizados três animaisteste e um número variável de reguladores por repetição, visando a manter a massa de forragem entre $1.200 \mathrm{e}$ $1.500 \mathrm{~kg} \mathrm{ha}^{-1}$ de matéria seca (MS). O período de adaptação dos animais ao suplemento e ao local foi de 19 dias.

Os animais utilizados foram terneiras, cruzas Charolês-Nelore, de idade média inicial de oito meses e peso vivo de $125 \mathrm{~kg}$, pertencentes ao setor de Bovinocultura de Corte do Departamento de Zootecnia. Os animais receberam diferentes níveis de suplemento: 0; 0,3; 0,6 e 0,9\% do peso vivo (PV), em pastagem de aveia (A. strigosa) mais azevém (L. multiflorum), durante todo o ciclo da pastagem. O suplemento foi uma ração comercial (14\% PB; 18,8\% FDN; 85\% DIVMO; 78,2\% NDT), composta por farelo de soja, farelo de trigo e grão de milho, fornecida diariamente às 14 horas.

A massa da forragem (MF) foi determinada pela técnica de dupla amostragem, no início do período de pastejo e posteriormente a cada 14 dias. Em cada repetição, foram realizados cinco cortes rente ao solo e 20 estimativas visuais. Da amostra resultante destes cinco cortes, foi separada uma subamostra para determinação da composição botânica da pastagem, obtida através da separação manual. Os componentes da pastagem foram separados em: folha de azevém; folha de aveia; colmo de azevém; colmo de aveia e material morto. $\mathrm{O}$ porcentual de cada componente na MF foi calculado com a MS de cada componente, dividido pela MS da amostra total.

A oferta de forragem (OF) foi calculada através da divisão do valor da massa de forragem pelo número de dias do período mais a taxa diária de acúmulo de matéria seca, sendo este valor dividido pela carga animal e multiplicado por 100. Para a determinação da oferta de lâminas foliares (OLF), dividiu-se a disponibilidade diária de lâminas foliares (disponibilidade de forragem x porcentagem de lâminas foliares) pela carga animal (CA), e o valor obtido foi multiplicado por 100 .

Para a avaliação da taxa de acúmulo de MS, foram utilizadas três gaiolas de exclusão ao pastejo por repetição. As perdas de forragem foram determinadas conforme metodologia de HILLESHEIM (1987).

Para o cálculo do consumo estimado de MS, foi subtraído da produção total de MS ha-1 o valor, em $\mathrm{kg} \mathrm{ha}^{-1}$ de MS, da MF existente no final do período experimental e as perdas de forragem ocorridas durante o período de pastejo. Dividindo o consumo estimado de MS ha-1 pela carga animal média, obteve-se o consumo estimado de MS em \% do PV.

Ciência Rural, v.37, n.6, nov-dez, 2007. 
As avaliações de comportamento animal foram diurnas, das 6 às 19 horas, realizadas em quatro datas: 14/08, 15/09, 7/10 e 26/10. Foram utilizados oito avaliadores, divididos em plantões de quatro horas, ficando um observador responsável pela observação dos animais-teste de dois potreiros. Os registros foram efetuados a cada dez minutos, e constaram das atividades de pastejo, ruminação e permanência no cocho. Como tempo de pastejo foi considerado o período no qual ocorreu a prática de apreensão da forragem pelo animal, incluindo pequenos deslocamentos. O tempo de ruminação foi identificado através da cessação do pastejo, mas realização da atividade de mastigação. O tempo de ócio foi considerado o período no qual o animal mantinha-se em descanso. Foi registrado o número de visitas dos animais aos cochos, e o tempo de permanência no cocho foi considerado o tempo despendido no consumo de suplemento pelo animal e a sua permanência próximo ao cocho.

Foram registradas as taxas de bocadas dos animais-teste de cada tratamento, sendo estimadas a partir do tempo gasto pelo animal para realizar 20 bocadas. Para o cálculo do peso de bocado, dividiu-se o consumo diário de forragem por animal pelo número total de bocadas diárias (taxa de bocadas x tempo de pastejo; JAMIESON \& HODGSON, 1979b).

O delineamento experimental foi inteiramente casualizado em parcelas subdivididas no tempo, com quatro tratamentos e duas repetições de área. Para os parâmetros medidos na pastagem, os potreiros foram considerados as repetições e, para os parâmetros de comportamento ingestivo, os animais-teste foram as repetições. Em caso de interação entre níveis de suplemento e períodos foi realizado teste de regressão polinomial ao nível de 5\%. Os dados foram submetidos à análise de variância, ao Teste $\mathrm{F}$ a 5\% de significância e à correlação. Os dados da composição botânica da pastagem para os períodos avaliados foram submetidos à análise de ordenação (análise de coordenadas principais) através do programa estatístico MULTIV (PILLAR, 1997).

\section{RESULTADOS E DISCUSSÃO}

Na figura 1 é apresentado o diagrama de ordenação, com as variáveis da composição botânica e os componentes estruturais de aveia e azevém em função dos níveis de suplemento e períodos de utilização da pastagem. O diagrama explica $90 \%$ da variação total das variáveis estudadas. Os componentes deste diagrama referem-se ao período de
26/07 a 29/10/2004, posterior à adaptação dos animais ao local e ao suplemento.

A mudança na composição estrutural da pastagem, em função dos níveis de suplemento fornecidos aos animais, pode ser visualizada no início do período de pastejo (P1; 26 dias). Nesta ocasião, a quantidade de folhas de aveia (FAv) e de folhas de azevém (FAz) foi maior, quando os animais receberam 0,6 e $0,9 \%$ do PV de suplemento, sugerindo que a maior participação do concentrado na dieta dos animais reduziu o consumo desses componentes. A contribuição de lâminas foliares de azevém foi de 785,2 $\mathrm{kg} \mathrm{ha}^{-1} \mathrm{MS}$ para S-0,9, enquanto que para SS e S-0,3 a contribuição foi de 243 e $145 \mathrm{~kg} \mathrm{ha}^{-1}$, respectivamente, o que foi decisivo na trajetória desse nível em relação aos demais.

A partir do dia 27 (P2), as contribuições dos componentes da pastagem foram semelhantes nos diferentes níveis de suplemento, com tendência à maior contribuição de FAv e FAz, principalmente, se comparadas à dos colmos. O estado final da pastagem foi similar entre os níveis de suplemento utilizados, tendo os tratamentos mudado apenas a sua trajetória inicial. FRIZZO et al. (2003) observaram maior percentual de FAv com nível de suplemento de 1,4\% do $\mathrm{PV} \mathrm{dia}{ }^{-1}$ e este percentual decresceu à medida que foram reduzidos os níveis de suplemento. Conforme estes autores, quanto maior o nível de suplemento, menor foi a percentagem do componente FAz na pastagem, demonstrando maior seletividade dos animais para esse componente.

Os componentes FAv e FAz estiveram presentes em maiores quantidades entre 01 e 54 dias de utilização da pastagem (períodos 1 e 2). Essa maior quantidade é conseqüência do estágio fisiológico das plantas, no qual a massa de forragem é predominantemente composta por folhas, mantendo elevada relação folha/colmo.

O diagrama mostra que, à medida que o ciclo de pastejo avança, há tendência do aumento da presença de colmos, principalmente de aveia, reduzindo a relação folha/colmo, seja pela seletividade do pastejo e/ou pelo aumento de material estrutural no dossel da pastagem.

Ao final do ciclo de pastejo houve uma maior participação de colmo de azevém (CAz), juntamente com material morto (MM). A maior presença de MM deve-se à maior translocação de fotoassimilados das partes inferiores do dossel das plantas para a parte superior e órgãos reprodutores, influenciado pelo final de ciclo da pastagem e também pela morte de plantas.

Houve interação entre níveis de suplemento e períodos para tempo total de permanência no cocho 


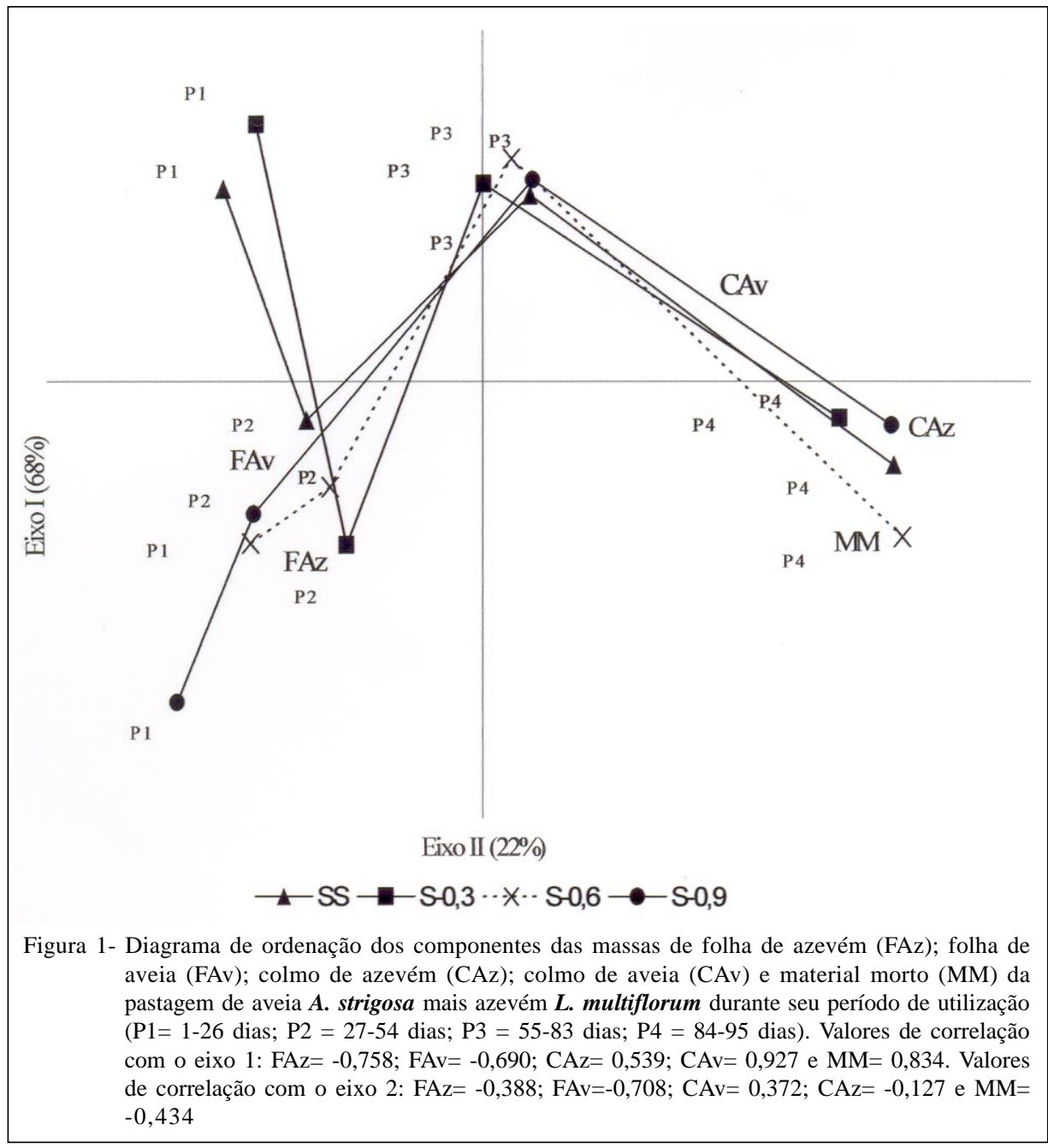

(TC) $(\mathrm{P}<0,05)$. O número de visitas diárias, com média de cinco, e o tempo médio de cada visita, 6 minutos, não foram influenciados pelos níveis de concentrado. A regressão quadrática foi a que melhor explicou a variação no tempo de permanência no cocho em $\mathrm{S}-0,3$ (S0,3 = 50,066 - 1,526x +0,015x2; $\mathrm{P}=0,0040 ; \mathrm{R} 2=41,4 \%)$. Nos primeiros 51 dias, pode ser observada redução de 1,52 minutos por dia no tempo de permanência no cocho dos animais. Nesta ocasião, houve acréscimo na carga animal de 6,13\% com relação ao período de adaptação, provavelmente proporcionando maior velocidade de consumo pela maior competição devido à pequena quantidade de suplemento fornecida. Após 51 dias de pastejo, existiu aumento de 0,015 minutos por dia no tempo de permanência no cocho, provavelmente devido à menor acessibilidade de um conteúdo satisfatório de folhas. Em S-0,6, a regressão não foi significativa $(\mathrm{P}>0,05)$ e, em $\mathrm{S}-0,9$, os animais reduziram o tempo de permanência no cocho em 0,33 minutos por dia (S0,9= 56,797-0,337x; P=0,0017; R2=36,8\%). Não houve correlação $(P>0,05)$ do TC com as variáveis da pastagem. BREMM et al. (2005) observaram maior número de visitas ao cocho com o aumento do nível de suplemento.

Houve interação entre níveis de suplemento e períodos para taxa de bocadas (TB; bocada minuto-1) e peso de bocado (PBC; g matéria orgânica (MO) bocado $\left.^{-1} ; \mathrm{P}<0,05\right)$. Variações nas características da pastagem em função do ciclo vegetativo da aveia e do azevém afetaram de forma diferente a TB dos animais com diferentes níveis de suplemento $(\mathrm{P}<0,05)$. A taxa e o peso de bocado em função dos dias de utilização da pastagem foram mais bem representadas através de equações de regressão ( $\mathrm{P}<0,05$; Figura $2 \mathrm{a}$ e $2 \mathrm{~b})$.

Os valores da TB dos animais exclusivamente em pastagem e dos que receberam $0,3 \%$ do PV dia ${ }^{-1}$ de suplemento se ajustaram ao modelo quadrático, atingindo o ponto máximo respectivamente aos 50 e 56 dias de utilização da pastagem, coincidindo com a maior disponibilidade de folhas (Figura 2b). O 


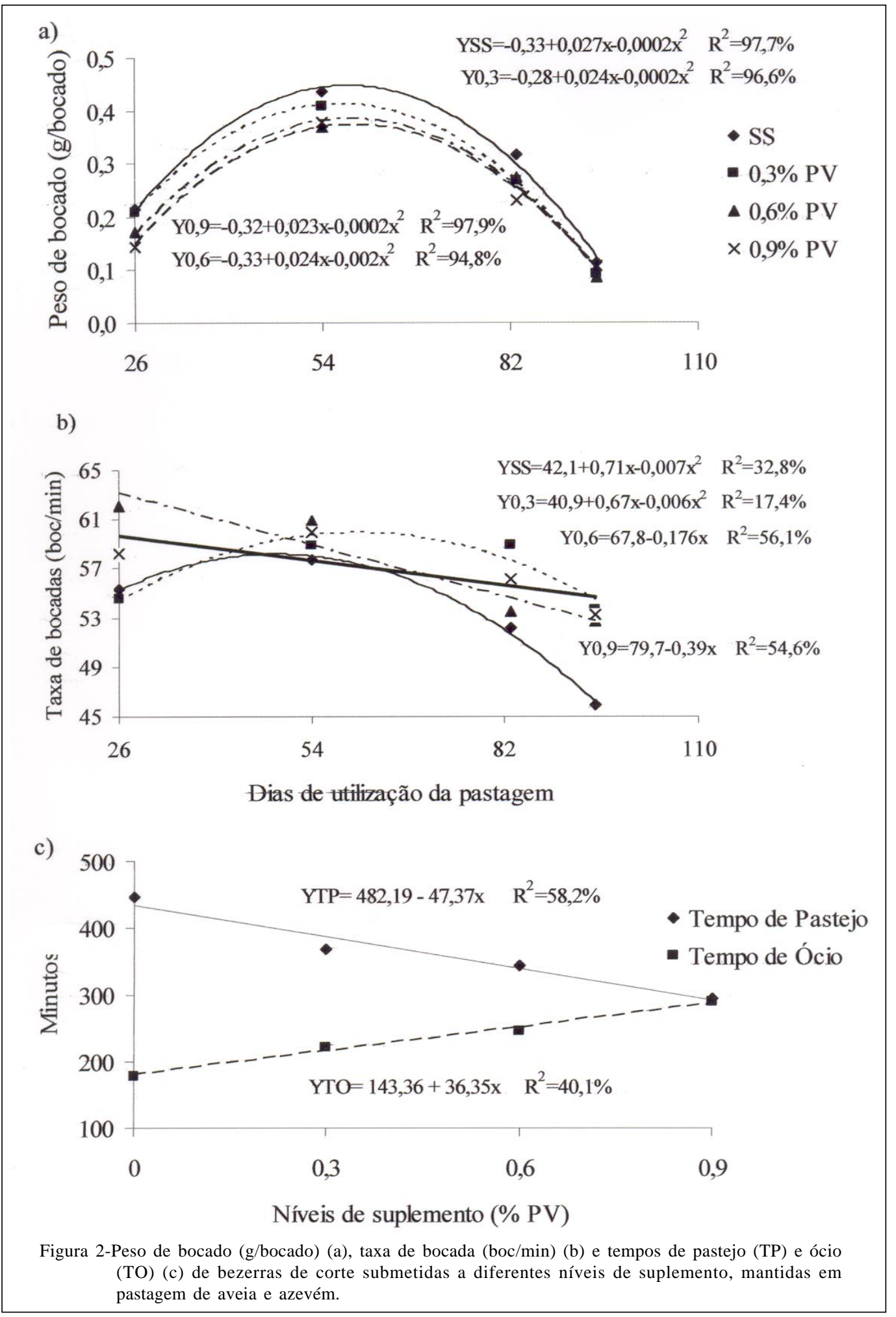

aumento na TB pode funcionar como mecanismo compensatório com objetivo de manter constante o tamanho de bocado, o que não seria esperado quando há predominância de folhas, que são consumidas preferencialmente pelos animais em pastejo (HODGSON, 1990). Com níveis maiores de suplemento, 0,6 e $0,9 \%$ do PV dia ${ }^{-1}$, o melhor ajuste foi para o modelo linear negativo, diminuindo respectivamente 0,176 e 
0,390 bocada min $^{-1}$ a cada dia do ciclo das forrageiras. Isso provavelmente possa ser explicado pela maior participação do suplemento na dieta, pois, no decorrer do ciclo, aumentou a participação de colmos e MM, que seriam responsáveis pelo aumento na TB (BRÂNCIO et al., 2003). Como as MF foram crescentes, a maior MF no final do ciclo também deve ter interferido na redução da taxa de bocada $(\mathrm{r}=-0,69 ; \mathrm{P}=0,0001)$.

O peso do bocado foi variável durante o período de utilização da pastagem, com valor inicial de 0,21 boc $^{-1} \mathrm{MO}$, para 0 e $0,3 \%$ do PV dia ${ }^{-1}$ (Figura 2a). Num período de 10 dias, compreendido entre os dias 57 e 67 de utilização da pastagem, foram observados os maiores PBC, sendo os valores superiores, em todos os níveis de suplemento, ao valor de 0,064g, encontrado por PEDROSO et al. (2004), trabalhando com ovinos, em pastagem de azevém. Conforme o diagrama de ordenação (Figura 1), no entanto, este período não corresponde à maior participação de lâminas foliares na pastagem. O peso de bocado mostrou correlação de $0,54(\mathrm{P}=0,0031)$ com FAz.

Não houve interação entre níveis de suplemento e períodos para tempos de pastejo (TP) e ócio (TO) $(\mathrm{P}>0,05)$. Variações nas características da pastagem em função do ciclo vegetativo da aveia e do azevém não afetaram o TP e o TO dos animais $(\mathrm{P}>0,05)$.

Os valores médios de oferta de forragem foram de $12,4 \mathrm{~kg}$ MS por $100 \mathrm{~kg}$ peso vivo (PV) e o de oferta de folhas de 4,3kg MS por $100 \mathrm{~kg}$ PV. Conforme HODGSON (1990), ofertas diárias de matéria seca de 10 a $12 \%$ do PV permitiriam o máximo desempenho individual de animais em pastejo, não tendo existido, portanto, limitações ao consumo voluntário de forragem decorrentes do manejo da pastagem.

As equações de regressão (Figura 2c) mostram as variações nos TP e TO de bezerras de corte quando submetidas a diferentes níveis de suplemento. À medida em que foi aumentada a quantidade de suplemento fornecido, os animais reduziram o TP e aumentaram o TO. Animais exclusivamente em pastagem pastejaram 410,75 minutos dia $^{-1}$, semelhante ao TP médio, 409,12 minutos, nos quatro níveis de suplemento, observado por BREMM et al. (2005) num período de 24 horas, também em pastagem de aveia e azevém. O fornecimento de suplemento proporcionou reduções no TP dos animais de 17,31, 22,83 e 33,57\%, respectivamente para os níveis 0,3; 0,6 e 0,9\% do PV. BREMM et al. (2005) observaram que o TP dos animais exclusivamente em pastagem foi superior 22,3, 22,8 e $40,2 \%$ ao TP de animais que receberam suplemento a 0,5, 1,0 e 1,5\% do PV, respectivamente, correspondendo a 115,84, 118,54 e 209,04 minutos a mais de TP. Essas reduções observadas no TP dos animais que receberam suplemento sugerem que há redução no gasto de energia associado ao pastejo, já relatado por PATIÑO PARDO et al. (2003).

O tempo de ruminação não diferiu entre níveis de suplemento e períodos ( $\mathrm{P}>0,05)$, sendo, em média, de 159,56 minutos. Provavelmente, a semelhança entre TR para os diferentes níveis de suplemento e períodos é consequência do horário das observações realizadas, as quais correspondem apenas ao turno diurno. A atividade de ruminação é mais consistente durante a madrugada, conforme GORDON \& McALLISTER(1970).

\section{CONCLUSÕES}

A composição botânica e estrutural da pastagem de aveia (A. strigosa Schreb.) e azevém (L.multiflorum Lam.) utilizada por bezerras de corte está relacionada com o ciclo de produção das forrageiras, sendo influenciada por níveis de suplemento apenas no início da utilização.

Em pastagem de aveia e azevém, o aumento da quantidade de suplemento fornecido aos animais em pastejo modifica o comportamento ingestivo diurno de bezerras de corte, através da redução no tempo de pastejo e do aumento no tempo de ócio, sem afetar o tempo de ruminação.

Diferentes níveis de suplemento condicionam de forma distintas as taxas de bocadas dos animais durante o decorrer do ciclo da pastagem.

\section{AGRADECIMENTOS}

À Fundação de Amparo à Pesquisa do Estado do Rio Grande do Sul (FAPERGS), pelo financiamento parcial deste trabalho.

\section{REFERÊNCIAS}

BRÂNCIO, P.A. et al. Avaliação de três cultivares de (Panicum maximum Jacq.) sob pastejo: comportamento ingestivo de bovinos. Revista Brasileira de Zootecnia, v.32, n.5, p.10451053, 2003.

BREMM, C. et al. Tempo de pastejo de bezerras de corte em pastagem de inverno sob níveis de suplementação energética. In: REUNIÃO ANUAL DA SOCIEDADE BRASILEIRA DE ZOOTECNIA, 41., 2004, Campo Grande. Anais... Campo Grande: Sociedade Brasileira de Zootecnia/Macromedia, [2004]. CD-ROM.

BREMM, C. et al. Efeito de níveis de suplementação sobre o comportamento ingestivo de bezerras em pastagem de aveia (Avena strigosa Schreb.) e azevém (Lolium multiflorum Lam.). Revista Brasileira de Zootecnia, v.34, n.2, p.387-397, 2005.

FRIZZO, A. et al. Produção de forragem e retorno econômico da pastagem de aveia e azevém sob pastejo com bezerras de corte submetidas a níveis de suplementação energética. Revista Brasileira de Zootecnia, v.32, n.3, p.632-642, 2003.

Ciência Rural, v.37, n.6, nov-dez, 2007. 
GORDON, J.G.; Mc ALLISTER, I.K. The circadian rhythm of rumination. Journal of Agricultural Science, v.74, n.2, p.291-297, 1970 .

HILLESHEIM, A. Fatores que afetam o consumo e perdas de Capim elefante (Pennisetum purpureum Schum) sob pastejo. 1987. 94f. Dissertação (Mestrado em Zootecnia)Escola Superior de Agricultura Luiz de Queiroz, ESALQ, Piracicaba.

HODGSON, J. Grazing management. Science into practice. England: Longman Scientific \& Technical, 1990. 203p.

JAMIESON, W.S.; HODGSON, J. The effect of daily herbage allowance and sward characteristics upon the ingestive behavior of calves under strip-grazing management. Grass and Forage Science, v.34, p.261-271, 1979a.

JAMIESON, W.S.; HODGSON, J. The effect of variation in sward characteristics upon the ingestive behavior and herbage intake of calves and lambs under continuous stocking management. Grass and Forage Science, v.34, p.273-281, 1979b.

PATIÑO PARDO, N.M. et al. Comportamento ingestivo diurno de novilhos em pastejo submetidos a níveis crescentes de suplementação energética. Revista Brasileira de Zootecnia, v.32, n.6, p.1408-1418, 2003.

PEDROSO, C.E.S. et al. Comportamento de ovinos em gestação e lactação sob pastejo em diferentes estádios fenológicos de azevém anual. Revista Brasileira de Zootecnia, v.33, n.5, p.1340-1344, 2004.

PILLAR, V.D.P. Multivariate exploratory analysis and randomization testing with MULTIV. Coenoses, v.12, p.145148, 1997.

ROSO, D. et al. Taxa de acúmulo e oferta de forragem em aveia mais azevém sob pastejo de bezerras recebendo suplementação energética. In: REUNIÃO ANUAL DA SOCIEDADE BRASILEIRA DE ZOOTECNIA, 40., 2003, Santa Maria, RS. Anais... Santa Maria: Sociedade Brasileira de Zootecnia/ Macromedia, [2003]. CD-ROM. 